\title{
Simplified Comprehensive Scour Model compared to Erodibility Index Method
}

\author{
E.F.R. Bollaert \\ AquaVision Engineering, Ecublens, Switzerland
}

\begin{abstract}
This paper presents a simplified application of the Comprehensive Scour Model (CSM) developed by Bollaert $(2002,2004)$. The CSM is a physics-based theoretical method used to estimate the scour potential in fractured rock. It allows the user to determine the time evolution of scour formation as well as the ultimate scour depth and the shape of the scour hole in a semi-3D manner. Despite its successful application to many dams worldwide over the last 15 years, one of the drawbacks of the method is its relative complexity of application and the wide range of values that can be used for basic input parameters. Hence, without any experience, sound application of the method may rapidly become challenging. Based on advanced modelling experiences acquired during the last 15 years with the CSM, this paper proposes a less complex and more straightforward application of the model. This Simplified Comprehensive Scour Model (SCSM) allows estimating the ultimate scour depth and its time evolution in a simple but theoretically still defendable manner. SCSM is compared with the popular and easily applicable semi-empirical Erodibility Index Method. Guidelines are provided for sound application of the method in practice.
\end{abstract}

\section{INTRODUCTION}

This paper presents a simplified application of the Comprehensive Scour Model (CSM) developed by Bollaert (2002, 2004). The CSM is a physics-based theoretical method used to estimate the scour potential in fractured rock. The method is based on prototype-scaled jet and plunge pool laboratory tests and considers different concepts of break-up of the rock mass (i.e. instantaneous or time-dependent fracturing, dynamic ejection of rock blocks and peeling off of rock blocks). It allows the user to determine the time evolution of scour formation as well as the ultimate scour depth and the shape of the scour hole in a semi-3D manner.

Despite its successful application to many dams worldwide over the last 15 years, one of the drawbacks of the method is its relative complexity of application and the wide range of values that can be used for basic input parameters. Hence, without any experience, sound application of the method may rapidly become challenging. Furthermore, without knowledge on the range of values to be used for the parameters, successful application asks for detailed calibration based on historic scour observations at the site in question.

Based on advanced modelling experiences acquired during the last 15 years with the CSM, this paper proposes a less complex and more straightfor- ward application of the model. This Simplified Comprehensive Scour Model (SCSM) still considers fracturing and uplift of rock blocks, but only allows estimating the ultimate scour depth in a simpler but theoretically still defendable manner. Complex model calibration and detailed 3D shapes of scour holes are not accounted for.

The SCSM is compared with the popular and easily applicable semi-empirical Erodibility Index Method. A benchmarking case study allows determining the sensitivity of the ultimate scour depth to some of the main parameters of interest of the CSM, such as the Unconfined Compressive Strength (UCS) of the rock mass, the initial degree of fracturing of the rock mass, the fracture mechanics fatigue law, the global shape of the rock blocks, etc.

\section{COMPREHENSIVE SCOUR MODEL (CSM)}

The Comprehensive Scour Model comprises three methods that describe failure of jointed rock. The Comprehensive Fracture Mechanics (CFM) method determines the ultimate scour depth by expressing instantaneous or time-dependent joint propagation due to water pressures inside the joint. The Dynamic Impulsion (DI) method describes the ejection of rock blocks from their mass due to sudden uplift pressures. The Quasi-Steady Impulsion Model (QSI) de- 
scribes peeling off of rock blocks from their mass by quasi-steady wall jet flows.

The structure of the Comprehensive Scour Model consists of three modules: the falling jet, the plunge pool and the rock mass. The latter module implements the aforementioned failure criteria. More details on equations can be found in Bollaert (2004).

\subsection{The module of the falling jet}

This module describes how the hydraulic and geometric characteristics of the jet are transformed from dam issuance down to the plunge pool (Fig. 1). Three parameters characterize the jet at issuance: the velocity $V_{i}$, the diameter (or width) $D_{i}$ and the initial turbulence intensity $\mathrm{T}_{\mathrm{u}}$, defined as the ratio of velocity fluctuations to the mean velocity. The jet trajectory is based on ballistics and air drag. The jet module computes the longitudinal location of impact, the total trajectory length $\mathrm{L}$ and the velocity and diameter at impact $\mathrm{V}_{\mathrm{j}}$ and $\mathrm{D}_{\mathrm{j}}$.

\subsection{The module of the plunge pool}

This module describes the characteristics of the jet when traversing the plunge pool and defines the water pressures at the water-rock interface. The ratio of water depth to jet diameter at impact $Y / D_{j}$ is directly related to jet diffusion. The most relevant pressures are the mean dynamic pressure coefficient $\mathrm{C}_{\mathrm{pa}}$ and the root-mean-square (rms) coefficient of the fluctuating dynamic pressures $\mathrm{C}_{\mathrm{pa}}^{\prime}$, both measured at the jet centerline. These coefficients correspond to the ratio of pressure head (in [m]) to incoming kinetic energy of the jet $\left(V^{2} / 2 g\right)$.

\subsection{The module of the rock mass}

The main parameters of this module are:

1. maximum dynamic pressure coefficient $\mathrm{C}^{\max }{ }_{\mathrm{p}}$

2. characteristic amplitude of pressure cycles $\Delta \mathrm{p}_{\mathrm{c}}$

3. characteristic frequency of pressure cycles $f_{c}$

4. maximum dynamic impulsion coefficient $\mathrm{C}_{\max I}$

The first parameter is relevant to brittle propagation of closed-end rock joints. The second and third parameters express time-dependent propagation of closed-end rock joints. The fourth parameter is used to define dynamic uplift of rock blocks formed by open-end rock joints. The maximum pressure $\mathrm{C}_{\operatorname{maxp}}$ is obtained through multiplication of the rms pressure $\mathrm{C}_{\mathrm{pa}}^{\prime}$ with an amplification factor $\Gamma^{+}$, and by superposition with the mean pressure $\mathrm{C}_{\mathrm{pa}}$. $\Gamma^{+}$expresses the ratio of the peak value inside the rock joint to the rms value of pressures at the pool bottom and has been determined based on prototype-scaled experiments (Bollaert, 2004). The product of $\mathrm{C}_{\mathrm{pa}}^{\prime}$ times $\Gamma^{+}$ results in a maximum pressure $\mathrm{P}_{\max }$, written as:
$P_{\max }[M P a]=10^{-6} \cdot \rho \cdot\left(C_{p a}+\Gamma^{+} \cdot C_{p a}^{\prime}\right) \cdot \frac{V_{j}^{2}}{2}$

in which $\rho$ stands for the density of the water in $\mathrm{kg} / \mathrm{m}^{3}$. The characteristic amplitude of the pressure cycles, $\Delta \mathrm{p}_{\mathrm{c}}$, is determined by the maximum and minimum pressures of the cycles. The characteristic frequency of pressure cycles $f_{c}$ follows the assumption of a perfect resonator system and depends on the air concentration in the joint $\alpha_{i}$ and on the length of the joint $\mathrm{L}_{\mathrm{f}}$. These parameters are used by three methods to express rock break-up, they are discussed below.

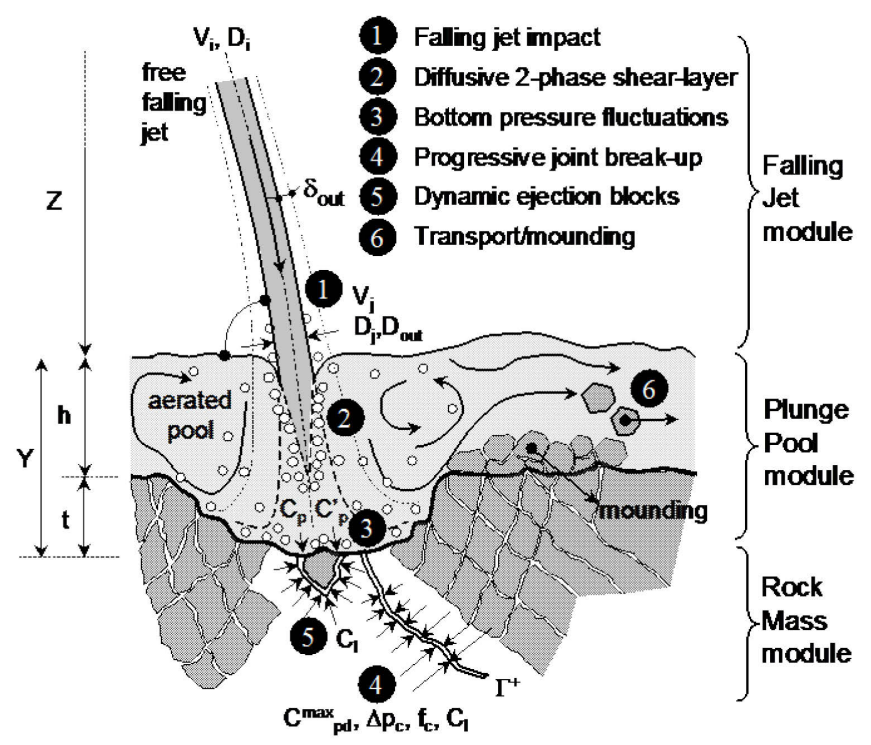

Figure 1: Parameters of Scour Model (Bollaert, 2004)

\section{Fracture Mechanics method}

The cyclic character of pressures generated by jets makes it possible to describe joint propagation by fatigue stresses occurring at the tip of the joint. A simplified methodology (Bollaert, 2004) is called the Comprehensive Fracture Mechanics (CFM) method and applicable to any partially jointed rock. Pure tensile pressure loading inside rock joints is described by the stress intensity factor $\mathrm{K}_{\mathrm{I}}$, representing the amplitude of rock mass stresses generated by water pressures at the tip of the joint. The corresponding resistance of the rock mass against joint propagation is expressed by its fracture toughness $\mathrm{K}_{\mathrm{Ic}}$.

Joint propagation distinguishes between brittle (or instantaneous) and time-dependent joint propagation. The former happens for a stress intensity factor equal to or higher than the fracture toughness. The latter is occurring when the maximum possible water pressure results in a stress intensity that is inferior to the material's resistance. Joints may then be propagated by fatigue. Failure by fatigue depends on the frequency and the amplitude of the load cycles. The fracture mechanics implementation of the hydrodynamic loading consists of a transformation of the water pressures in the joints into stresses in the rock. These stresses are characterized by $\mathrm{K}_{\mathrm{I}}$ as follows: 
$K_{I}=0.8 \cdot P_{\max } \cdot F \cdot \sqrt{\pi \cdot L_{f}}$

in which $\mathrm{K}_{\mathrm{I}}$ is in $\mathrm{MPa} \sqrt{\mathrm{m}}$ and $\mathrm{P}_{\max }$ in $\mathrm{MPa}$. A reduction factor of 0.8 is applied to account for a varying value of Pmax throughout the joint length (parabolic-shaped pressure distribution).

The boundary correction factor $\mathrm{F}$ depends on the type of crack and on its persistency, i.e. its degree of cracking defined as $\mathrm{a} / \mathrm{B}$ or $\mathrm{b} / \mathrm{W}$ in Fig. 2. This figure presents basic configurations for partially jointed rock. The choice of the most relevant geometry depends on the type and the degree of jointing.

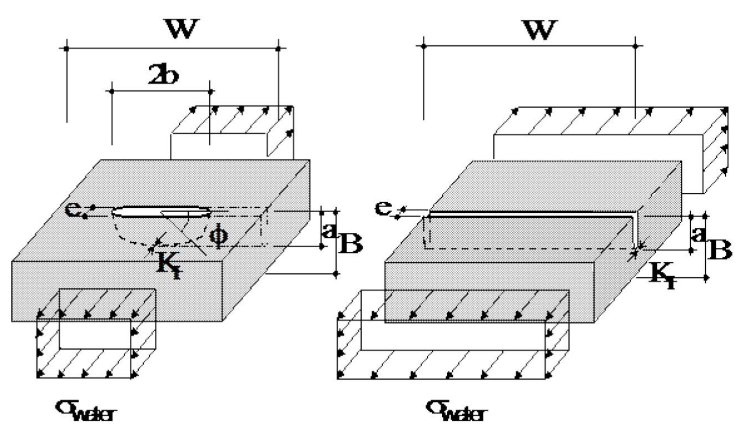

Figure 2: Rock joint configurations of CSM model

For practice, $\mathrm{F}$ values of 0.5 or higher are considered to correspond to completely broken-up rock. For values of 0.1 or less, a tensile strength approach is more plausible.

The fracture toughness $K_{I c}$ is related to the mineralogical type of rock and to the unconfined compressive strength UCS. Furthermore, corrections are made to account for the loading rate and the in-situ stress field. The corrected fracture toughness is defined as the in-situ fracture toughness $\mathrm{K}_{\mathrm{I} \text {,ins }}$ and is based on a linear regression of available literature data. More detailed equations, as a function of the mineralogical rock composition, can be found in Bollaert (2002).

$K_{\text {Iins, } U C S}=(0.008$ to 0.010$) \cdot U C S+\left(0.054 \cdot \sigma_{c}\right)+0.42$

in which $\sigma_{\mathrm{c}}$ represents the confinement horizontal in-situ stress and UCS and $\sigma_{c}$ are in MPa. Timedependent joint propagation is expressed by an equation originally proposed to describe fatigue growth in metals:

$$
\frac{d L_{f}}{d N}=C_{r} \cdot\left(\Delta K_{I} / K_{I c}\right)^{m_{r}}
$$

in which $\mathrm{N}$ is the number of pressure cycles. $\mathrm{C}_{\mathrm{r}}$ and $\mathrm{m}_{\mathrm{r}}$ are material parameters that are determined by fatigue tests and $\Delta \mathrm{K}_{\mathrm{I}}$ is the difference of maximum and minimum stress intensity factors. To implement time-dependent joint propagation into the model, $\mathrm{m}_{\mathrm{r}}$ and $\mathrm{C}_{\mathrm{r}}$ have to be known. They represent the vulner- ability of rock to fatigue and can be derived from available literature data.

\section{Dynamic Impulsion method}

The fourth dynamic loading parameter is the maximum dynamic impulsion $\mathrm{C}_{\max }$ underneath a rock block, obtained by time integration of the net forces on the block (Newton):

$$
I=\int_{0}^{\Delta t p u l s e}\left(F_{u}-F_{o}-G_{b}-F_{s h}\right) \cdot d t=m \cdot V_{\Delta t p u l s e}
$$

in which $F_{u}$ and $F_{o}$ are the forces under and over the block, $G_{b}$ is the immerged weight of the block and $\mathrm{F}_{\text {sh }}$ represents the shear and interlocking forces.

The first step is to define the maximum net impulsion $\mathrm{I}_{\max }$ as the product of a net force and a time period. The corresponding pressure is made nondimensional by the jet's kinetic energy $\mathrm{V}^{2} / 2 \mathrm{~g}$. This results in a net uplift pressure coefficient $\mathrm{C}_{\text {up }}$. The time period is non-dimensionalized by the travel period that is characteristic for pressure waves inside rock joints, i.e. $T=2 \cdot \mathrm{L}_{\mathrm{f}} / \mathrm{c}$. This results in a time coefficient $\mathrm{T}_{\text {up }}$. Hence, the non-dimensional impulsion coefficient $\mathrm{C}_{\mathrm{I}}$ is defined by the product $\mathrm{C}_{\mathrm{up}} \cdot \mathrm{T}_{\text {up }}=$ $\mathrm{V}^{2} \cdot \mathrm{L} / \mathrm{g} \cdot \mathrm{c}[\mathrm{m} \cdot \mathrm{s}]$. The maximum net impulsion $\mathrm{I}_{\max }$ is obtained by multiplication of $\mathrm{C}_{\mathrm{I}}$ by $\mathrm{V}^{2} \cdot \mathrm{L} / \mathrm{g} \cdot \mathrm{c}$. Prototype-scaled analysis of uplift pressures resulted in the following expression for $\mathrm{C}_{\mathrm{I}}$ :

$$
C_{I}=0.0035 \cdot\left(\frac{Y}{D_{j}}\right)^{2}-0.119 \cdot\left(\frac{Y}{D_{j}}\right)+1.22
$$

Failure of a block is expressed by the displacement it undergoes due to the net impulsion $\mathrm{C}_{\mathrm{I}}$. This is obtained by transformation of $\mathrm{V}_{\Delta \text { tpulse }}$ in Eq.(5) into a net uplift displacement $h_{\text {up }}$.

\section{Quasi-Steady Impulsion method}

Finally, the quasi-steady impulsion method (QSI) describes the flow parallel to the bottom, outside of the impingement region of the jet (Bollaert, 2012). In case of protruding rock blocks along the bottom, the flow is deflected by these blocks, which generates turbulent pressure fluctuations. In contrast with turbulent wall pressures that are generated by turbulent eddies of the flow itself, these pressure fluctuations are of quasi-steady character (Bollaert \& Hofland, 2004). As such, they generate significant lift and drag forces on protruding rock blocks.

The deflection of the jet at the pool bottom occurs in both the up-and downstream directions. The importance of each of these deflections directly depends on the angle $\delta$ of the jet upon impact in the pool. As shown in Fig. 3, based on Reich (1927), a theoretical approach for plane jets with initial discharge $q_{\text {total }}$ and thickness $D_{j}$ impinging on a flat plate relates the respective discharges $\mathrm{q}_{\text {up }}$ and $\mathrm{q}_{\text {down }}$ and thicknesses $h_{\text {up }}$ and $h_{\text {down }}$ by means of the cosines of the jet angle with the horizontal $\delta$ : 
$\frac{q_{u p}}{q_{\text {total }}}=\frac{h_{u p}}{D_{j}}=\frac{1}{2} \cdot(1-\cos \delta)$
$\frac{q_{\text {down }}}{q_{\text {total }}}=\frac{h_{\text {down }}}{D_{j}}=\frac{1}{2} \cdot(1+\cos \delta)$

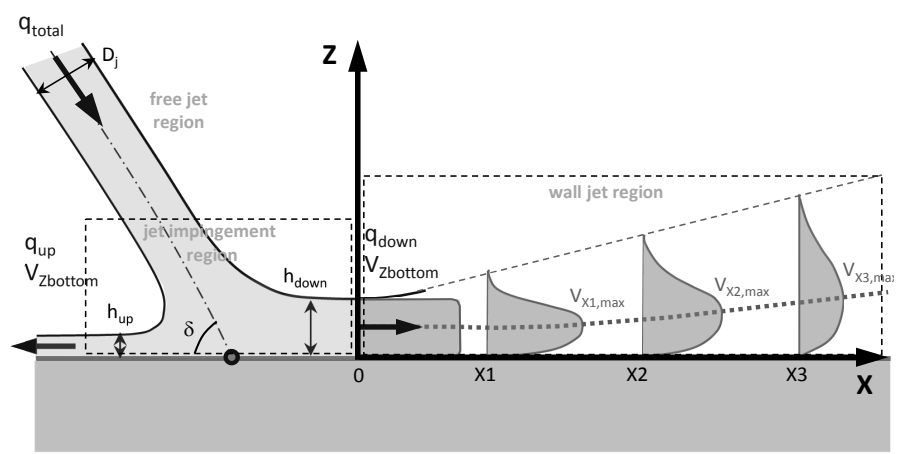

Figure 3: Plane jet deflection on a flat bottom (Reich, 1927)

Once the jet deflected, the wall jets may be characterized by their initial flow velocity $V_{\text {Zbottom }}$ and their initial thickness $h_{\text {up }}$ or $h_{\text {down }}$ at the point of deflection. Initiating from this singular location, the wall jets develop radially outwards following selfpreserving velocity profiles (Beltaos \& Rajaratnam, 1973) as given by the following equation:

$\frac{V_{X, \max }}{V_{\text {Zbottom }}}=\frac{3.5}{\sqrt{X / h_{\text {down }}}}$

$\mathrm{V}_{\text {Zbottom }}$ depends on the diffusion angle of the impinging jet and on its development length through the water depth $\mathrm{Z}$. $\mathrm{V}_{\text {Zbottom }}$ continuously changes during scour formation. $\mathrm{V}_{\mathrm{X} \text {,max }}$ expresses the decay of the maximum cross-sectional jet velocity with the relative distance from the start of the wall jet (lateral distance $\mathrm{X}$ divided by the initial thickness of the deflected jet $h_{\text {up }}$ or $h_{\text {down }}$ ).

This decreasing velocity is of direct relevance to the potential generation of quasi-steady stagnation pressures at rock blocks protruding along the pool bottom. Several researchers have defined this pressure by means of an uplift pressure coefficient $\mathrm{C}_{\text {uplift }}$ expressing the pressure as a percentage of the kinetic energy $\mathrm{V}_{\mathrm{z}, \mathrm{m}}^{2} / 2 \mathrm{~g}$ of the quasi-parallel flow deviated by the block.

\section{SIMPLIFIED COMPREHENSIVE SCOUR MODEL (SCSM)}

\subsection{Introduction}

The CSM is a relatively complex theoretical method, making use of a large number of parameters to be defined as input to the model. Hence, without any experience, sound application of the method may rapidly become challenging. Furthermore, with- out knowledge on the range of values to be used for the parameters, successful application asks for detailed calibration based on historic scour observations at the site in question.

In order to provide a more straightforward, firsthand assessment of rock scour potential, without calibration, a Simplified Comprehensive Scour Model (SCSM) is being presented. The SCSM still makes use of the basic theories behind the CSM, but proposes first-hand approximations for a number of parameters, and is restricted to scour potential at the jet impact point only. As such, only the fracturing and block uplift modules are considered.

\subsection{Simplification of main CSM modules}

The falling jet, plunge pool and rock mass modules of the CSM have been simplified to allow a straightforward step-by-step computation with depth in the following manner:

- Falling jet module: Define diameter $\mathrm{D}_{\mathrm{j}}$ and head $\mathrm{H}_{j}$ or velocity $\mathrm{V}_{\mathrm{j}}$ of jet at impact in water cushion. Compute head $\mathrm{H}_{\mathrm{j}}$ or velocity $\mathrm{V}_{\mathrm{j}}$ of jet following Eq. (9):

$$
H_{j}[m]=\frac{V_{j}^{2}}{2 g}
$$

- Plunge pool module: Define initial depth of water cushion $\mathrm{Y}$. Compute $\mathrm{C}_{\mathrm{p}}, \mathrm{C}_{\mathrm{p}}$ and $\mathrm{C}_{\max }$ pressure coefficients with depth $\mathrm{Y}$ based on Eqs. (10) to (13):

$$
\begin{gathered}
C_{p a}=38.4 \cdot\left(\frac{D_{j}}{Y}\right)^{2} \text { for } \mathrm{Y} / \mathrm{D}_{\mathrm{j}}>4-6 \\
C_{p a}=0.85 \quad \text { for } \mathrm{Y} / \mathrm{D}_{\mathrm{j}}<4-6 \\
C_{p a}^{\prime}=0.000215 \cdot\left(\frac{Y}{D_{j}}\right)^{3}-0.0079 \cdot\left(\frac{Y}{D_{j}}\right)^{2}+0.0716 \cdot\left(\frac{Y}{D_{j}}\right)+0.15 \\
\quad \text { for } 16>\mathrm{YDj}>0 \\
C_{p a}^{\prime}=0.010 \text { for } 25>\mathrm{Y} / \mathrm{D}_{\mathrm{j}}>16 \\
C_{p a}^{\prime}=0.005 \text { for } 40>\mathrm{Y} / \mathrm{D}_{\mathrm{j}}>25 \\
P_{\max }[P a]=\gamma \cdot C_{p}^{\max } \cdot \frac{V_{j}^{2}}{2 g}=\gamma \cdot\left(C_{p a}+\Gamma^{+} \cdot C_{p a}^{\prime}\right) \cdot \frac{V_{j}^{2}}{2 g} \\
\Gamma^{+}=4+2 \cdot \mathrm{Y} / \mathrm{D}_{\mathrm{j}} \quad \begin{array}{l}
\text { for } \mathrm{Y} / \mathrm{D}_{\mathrm{j}}<8 \\
\Gamma^{+}=20 \quad \text { for } 8 \leq \mathrm{Y} / \mathrm{D}_{\mathrm{j}} \leq 10 \\
\Gamma^{+}=40-2 \cdot \mathrm{Y} / \mathrm{D}_{\mathrm{j}} \quad
\end{array}
\end{gathered}
$$

- Rock mass module-Fracture Mechanics (CFM): For each depth Y, define the type of rock, the UCS strength, the initial degree of fissuring $\mathrm{a} / \mathrm{B}$ or $\mathrm{b} / \mathrm{W}$, the total fissure length $\mathrm{L}_{\mathrm{f}}$, the lateral support (planar 2D (SE) or elliptical 3D (EL) fissures), which defines the $F$ function in Eq. (2) as presented in Fig. 4. Use values of 
0.2-0.3 for low degree of fissuring, 0.4-0.5 for moderate fissuring, and 0.6 or more for high degree of fissuring. Compute the stress intensity $\mathrm{K}_{\mathrm{I}}$ following Eq. (2).

- Rock mass module-Fracture Mechanics (CFM): For each depth Y, compute the fracture toughness $\mathrm{K}_{\mathrm{Ic}}$ following Eq. (3) by neglecting the horizontal in-situ stresses $\sigma_{\mathrm{c}}$. Define wave celerity c between 100 (high air content) and 200 (low air content) $\mathrm{m} / \mathrm{s}$. Compute number of pressure cycles per sec as follows (max, $100 \mathrm{~Hz}$, consider no jet energy beyond):

$$
N[-]=\frac{c}{4(a / B) L_{f}}(\max .100 \mathrm{~Hz})
$$

Define the fatigue law coefficient $\mathrm{C}_{\mathrm{r}}$ and exponent $\mathrm{m}_{\mathrm{r}}$ as follows:

$\mathrm{C}_{\mathrm{r}}=1.10^{-4}-1.10^{-5} \quad / \mathrm{m}_{\mathrm{r}}=2-4 \quad$ values to be used for "soft" or easily erodible rock (high fracturing speed)

$\mathrm{C}_{\mathrm{r}}=1.10^{-6}-1.10^{-7} / \mathrm{m}_{\mathrm{r}}=6-9 \quad$ values to be used for "hard" or lowly erodible rock (low fracturing speed)

For each depth Y, compute fracturing speed FS following Eq. (4) and (14), by assuming $\mathrm{K}_{\mathrm{I}}=$ $\Delta \mathrm{K}_{\mathrm{I}}$.

$$
F S[m / h]=3600 \cdot N \cdot \frac{d L_{f}}{d N}
$$

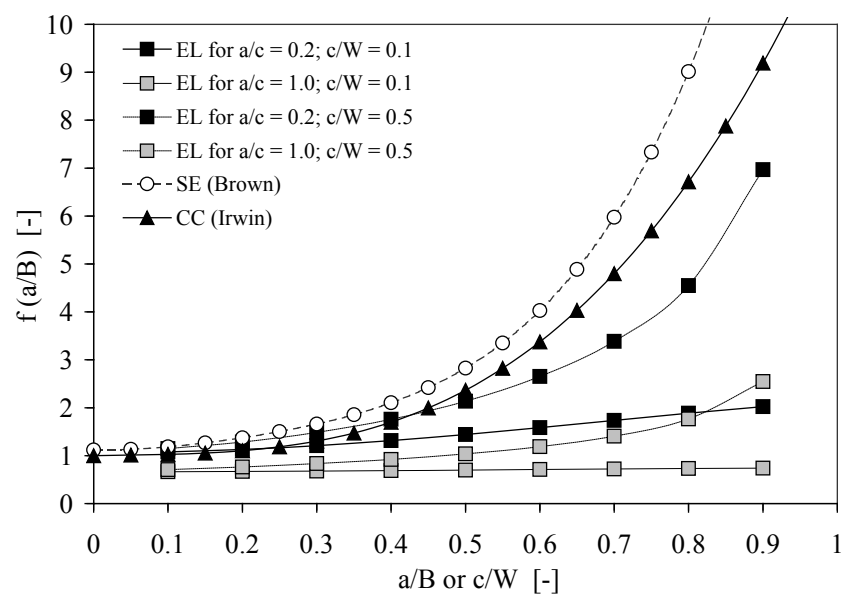

Figure 4 Comparison of different geometrical situations of joints on the theoretical stress intensity factor $\mathrm{K}_{\mathrm{I}}$.

- Rock mass module-Dynamic Impulsion (DI): define the ratio of block height $\mathrm{z}$ to block side length $x$, define the density of the block. For each depth Y, compute the uplift coefficient $\mathrm{C}_{\mathrm{I}}$ following Eq. (5). Compute the maximum net impulsion $\mathrm{I}_{\max }$ by multiplication of $\mathrm{C}_{\mathrm{I}}$ by $\gamma \mathrm{V}^{2} \cdot \mathrm{L} / \mathrm{g} \cdot \mathrm{c}$, in which $\mathrm{L}=\mathrm{x}+2 \mathrm{z}$. Based on large-scale laboratory experiments, assume the time coefficient $T_{\text {up }}=1.5$. By multiplying this coefficient with $\mathrm{T}=2 \cdot \mathrm{L}_{\mathrm{f}} / \mathrm{c}$, this results in a time duration valid for the uplift forces to act on the block. Compute the submerged weight of the block $\mathrm{m}_{\mathrm{s}}$.g and express the net uplift impulsion as follows:

$I_{\text {net }}=I_{\max }-T_{u p} \cdot 2 \cdot L_{f} / c \cdot g \cdot m_{s}$

Compute the net uplift velocity based on Eqs. (5) and (14) as follows:

$$
V_{\Delta t p u l s e}=\frac{I_{\text {net }}}{m_{s}}
$$

Next the net uplift velocity of the block is simply transformed into a net uplift height $h_{\text {up }}$ and a net uplift ratio $\mathrm{h}_{\mathrm{up}} / \mathrm{z}$ :

$$
h_{u p}=V^{2} \Delta t p u l s e / 2 g
$$

In the following, case studies are provided of application of the Simplified Comprehensive Scour Model (SCSM), by using both fracture mechanics (CFM) and block uplift (DI) methods to estimate the ultimate scour depth and the time evolution of scour formation. Comparison is made with the Erodibility Index Method (EIM).

\subsection{Fracture Mechanics method (CFM) applied to a highly fractured rock}

Figure 5 illustrates the computational results for a highly fractured rock with an initial degree of fissuring of $80 \%$ (EL joints, $\mathrm{L}_{\mathrm{f}}=1 \mathrm{~m}$ ), a UCS strength of $175 \mathrm{MPa}$, and impacted by a jet of diameter $7.5 \mathrm{~m}$ and an impact velocity of $30 \mathrm{~m} / \mathrm{s}$.

The hydraulic head at impact is of $45.9 \mathrm{~m}$, and the pressure coefficients and other computed parameters are presented as a function of water depth at Fig. 5.

For water depths between 48 and $72 \mathrm{~m}$, the stress intensity is larger than the fracture toughness of the rock mass. As such, hydraulic fracturing occurs quasi instantaneously during jet impact.

For other water depths, however, the stress intensity becomes less than the fracture toughness and time-dependent fracturing occurs. The corresponding fracture speeds FS are presented using the lower abscissa and show that for hard or low scour vulnerable rock, using a "slow" fatigue law $\mathrm{Cr}=5.10-7, \mathrm{mr}=6$, the FS quickly becomes very low.

This means that fatigue fracturing needs long durations of high discharge to occur, durations that might be beyond the lifetime of the dam. Ultimate scour is estimated at about $100 \mathrm{~m}$ of water depth.

On the other hand, for soft or scour vulnerable rock, using a "fast" fatigue law $\mathrm{Cr}=5.10-5, \mathrm{mr}=3$, the FS reduces much more slowly with increasing 
scour depth. Ultimate scour is estimated at about 120 $m$ of water depth.

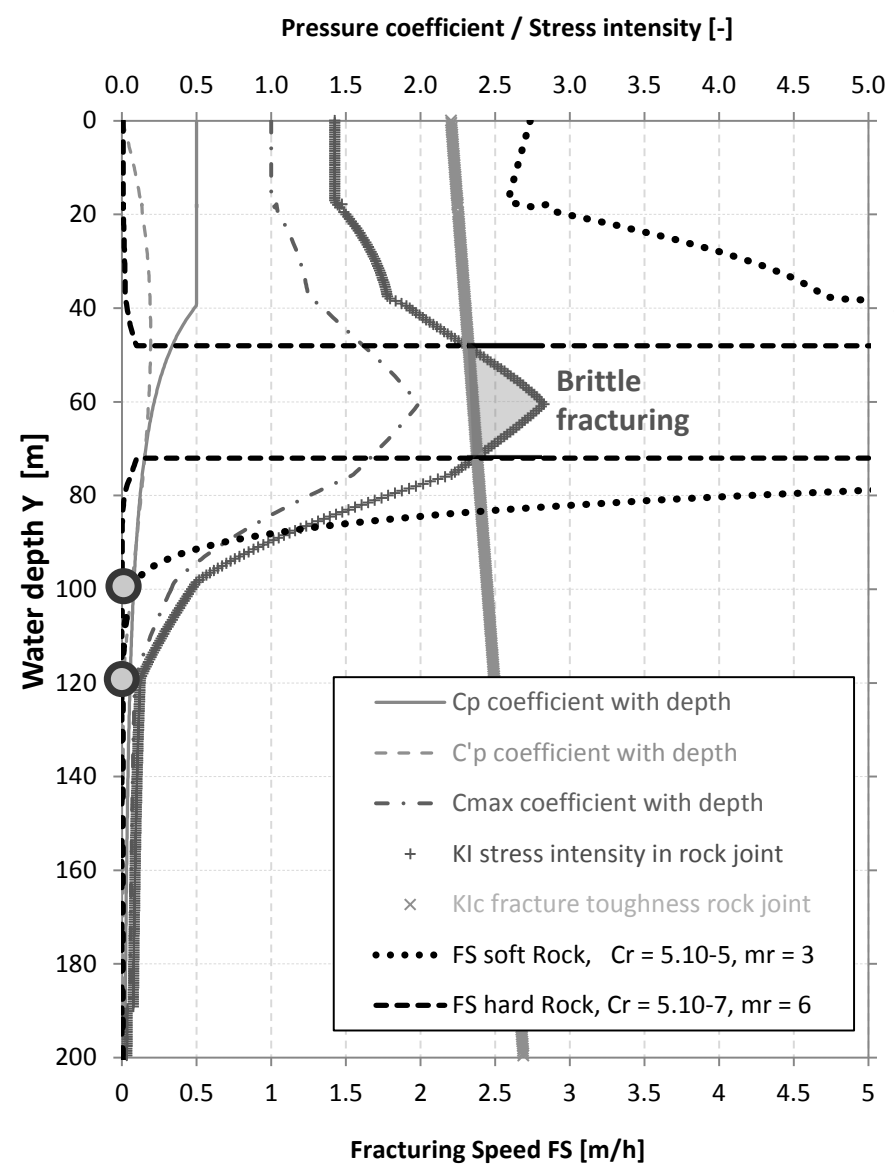

Figure 5 Computational results for a highly fractured rock

It is interesting to notice also that the ultimate scour depth for a soft or scour vulnerable rock coincides more or less with the water depth for which all pressure coefficients tend towards zero or, at least, towards a very low value. The graph does not inform, however, on the time duration of discharge needed to reach such a deep scour value, and whether these durations are plausible during the lifetime of the dam. This is shown in Fig. 7.

\subsection{Fracture Mechanics method (CFM) applied to a lowly fractured rock}

Figure 6 illustrates similar results but for a lowly fractured rock with an initial degree of fissuring of only $10 \%$. The other parameters remain similar.

For all water depths, the stress intensity is lower than the fracture toughness. As such, no brittle fracturing occurs and only time-dependent fracturing occurs.

While it may be observed that the computed fracturing speeds FS are significantly lower than for the highly fractured case, the ultimate scour depth estimates are only slightly smaller.

Again, the time duration needed to reach such deep scour formation is not presented on Fig. 6.

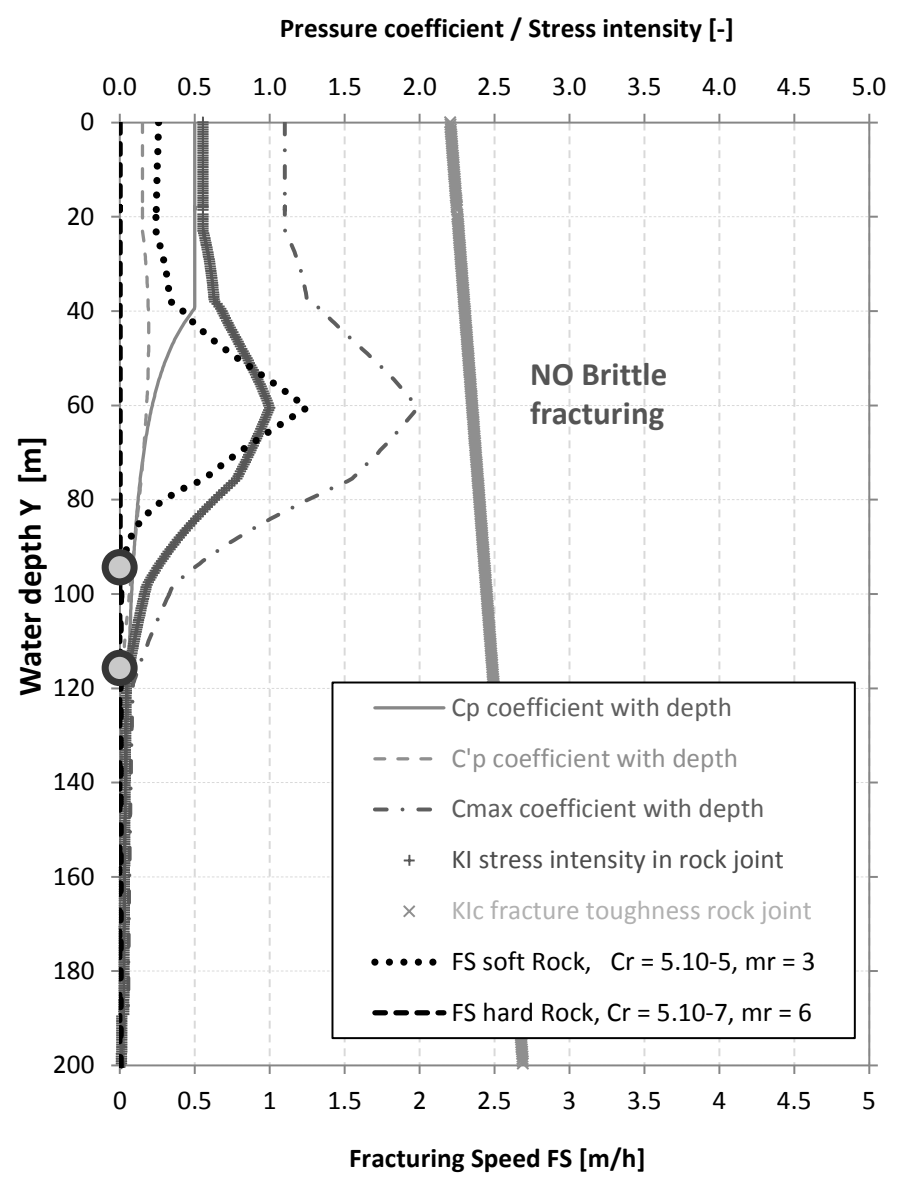

Figure 6 Computational results for a lowly fractured rock

\subsection{Time duration of ultimate scour depth by fracture mechanics method (CFM)}

While the ultimate scour depths are quite similar for both cases discussed above, the total time duration of jet impact needed to reach such depths is of course significantly different. This can be observed in Fig. 7, where a comparison is made of the time evolution of the scour formation for both lowly $(10 \%)$ and highly $(80 \%)$ fractured rocks with a fast fatigue law, i.e. scour vulnerable rock.

A scour depth of $100 \mathrm{~m}$ needs about $80 \mathrm{~h}$ of jet discharge for a highly fractured rock, while it needs more than $500 \mathrm{~h}$ of discharge for a lowly fractured rock. This is partly because of the brittle fracturing between $48 \mathrm{~m}$ and $72 \mathrm{~m}$ of depth in case of high fracturing.

Similarly, a scour depth of 110 m needs $400 \mathrm{~h}$ of discharge for a highly fractured rock and would never be reached for a lowly fractured rock. These time durations may does easily go well beyond the flow duration curves valid during the lifetime of the dam.

Hence, when applying the SCSM, it is particularly interesting to derive the time evolution curve, in order to check whether the computed ultimate depths are applicable within the lifetime of the dam. 


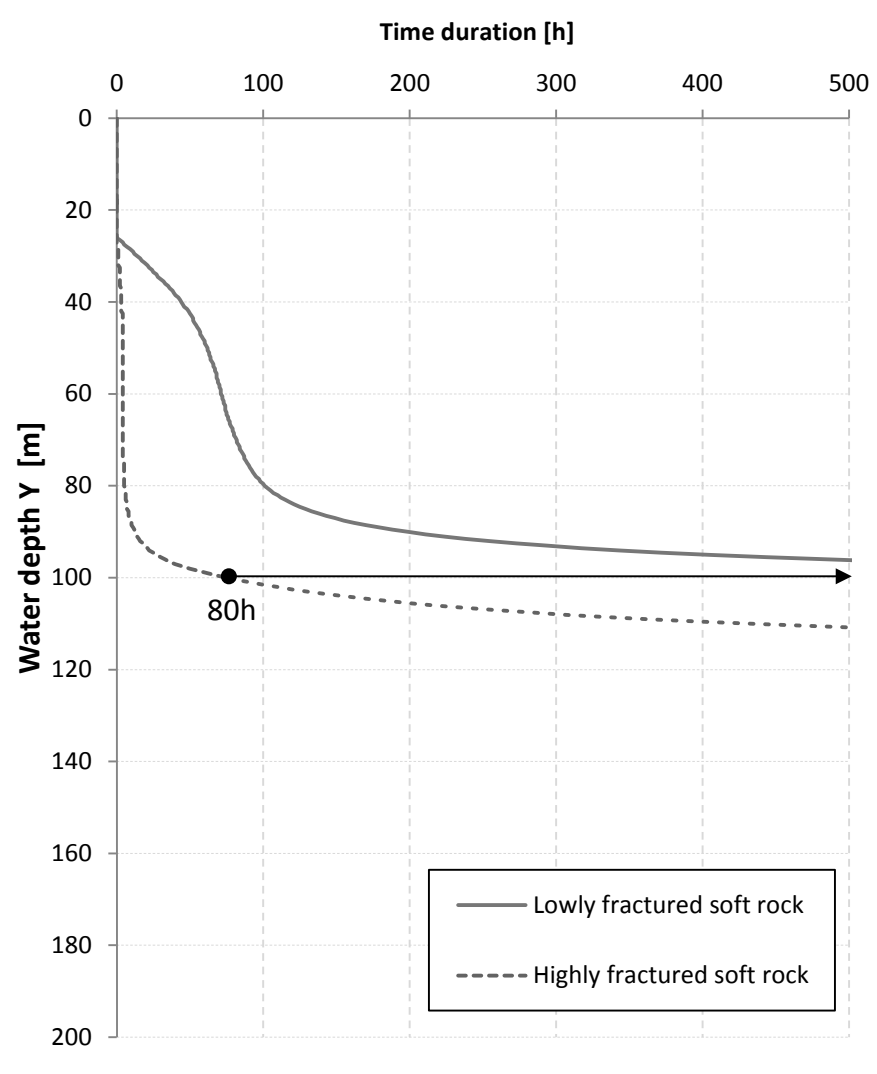

Figure 7 Time evolution of scour for an easily erodible rock

\subsection{Dynamic Impulsion method (DI) applied to flat- shaped rock blocks}

Next, the DI method is applied to the same rock mass described under $\S 3.4$. The rock mass is considered fully broken up into blocks with a height to side-length ratio of $0.5: 1$.

Fig. 8 illustrates the evolution with depth of the CI coefficient, the ratio $h_{u p} / z$, the net block uplift height $\mathrm{h}_{\mathrm{up}}$ and uplift velocity $\mathrm{V}_{\text {up }}$. By applying the criterion of a critical uplift ratio $h_{u p} / z$ of 0.20 , the ultimate scour depth is estimated at $95 \mathrm{~m}$. For smaller shaped blocks, a deeper ultimate scour depth would be computed.

\subsection{Summary of SCSM}

As a summary, the presented case studies point out the relative easiness to make estimates for both the ultimate scour depth and the time evolution of scour formation under the point of impact of the jet.

The parameters that have to be known or estimated to apply the SCSM are:

- Jet diameter and velocity upon impact

- Initial water cushion

- Type of rock mass

- UCS strength of rock mass

- Qualitative appreciation of the initial degree of fissuring of the mass (low, medium, high; persistency in \%), generally based on the RQD value and in-situ observations

- Qualitative appreciation of the type of fissures (elliptical with 3D support, planar 2D without lateral support), generally based on in-situ observations and/or geologic reports

- Density and relative shape of the rock blocks generally based on in-situ observations

It is believed that most or even all of these parameters are generally known within the framework of main hydraulic structures, or at least can be easily estimated based on in situ observations and basic rock mechanics testing procedures. In case no values are available, reasonable safe-side assumptions should be made based on literature data and in-situ observations.

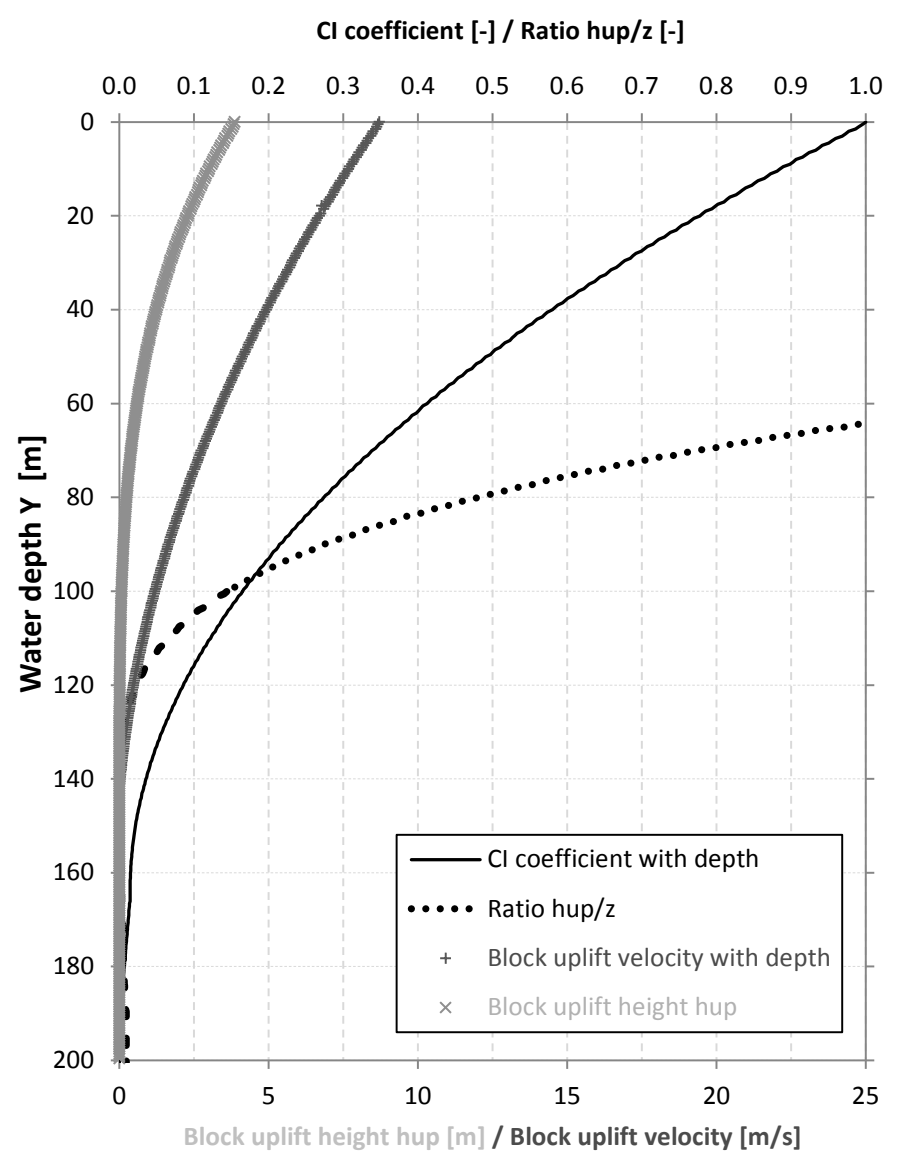

Figure 8 Computational results of dynamic block uplift 


\section{COMPARISON WITH ERODIBILITY INDEX METHOD (EIM)}

\subsection{Introduction}

Next, a comparison is made between the SCSM and the Erodibility Index Method (EIM). The EIM is a semi-empirical method making use of a geomechanical index that is used to quantify the relative ability of the rock mass to resist the erosive capacity of water (Annandale, 2006).

Application of the EIM is based on an erosion threshold that relates the relative magnitude of the erosive capacity of water, represented by the Stream Power (SP), and the erosion resistance of the rock mass represented by a mathematical function $f(K)$, in which $\mathrm{K}$ is the erodibility index. Both $\mathrm{SP}$ and $\mathrm{K}$ are defined as (Annandale, 2006):

$$
\begin{aligned}
& S P\left[k W / m^{2}\right]=7.853 \cdot \rho \cdot\left(\frac{\tau}{\rho}\right)^{3 / 2} \\
& \tau=\rho \cdot g \cdot \frac{1}{3} \cdot C_{p}^{\prime} \cdot \frac{V^{2}}{2 g} \\
& K=M_{s} \cdot K_{b} \cdot K_{d} \cdot J_{s}
\end{aligned}
$$

$\mathrm{M}_{\mathrm{s}}=$ mass strength number

$\mathrm{K}_{\mathrm{b}}=$ block size number $=\mathrm{RQD} / \mathrm{Jn}$

$\mathrm{J}_{\mathrm{n}}=$ joint set number

$\mathrm{K}_{\mathrm{d}}=$ discontinuity bond shear strength number $=\mathrm{J}_{\mathrm{r}} / \mathrm{J}_{\mathrm{a}}$

$\mathrm{J}_{\mathrm{r}}=$ joint roughness number

$\mathrm{J}_{\mathrm{a}}=$ joint alteration number

$\mathrm{J}_{\mathrm{s}}=$ relative ground structure number

In Eq. (21), the different terms on the right hand side can be found in tables and are based on the type of rock and its joint patterns (Annandale, 2006).

If $\mathrm{SP}>\mathrm{f}(\mathrm{K})$, the erosion threshold is exceeded and the rock material is expected to erode. If not, the rock material is expected to not erode. Eq. (21) was originally developed by Kirsten (1982), to characterize the excavatability of earth materials.

Annandale (1995) found that it also applies to fluvial erosion of earth and rock materials and established a relationship between the critical stream power $\mathrm{SP}_{\mathrm{c}}$ and the erodibility index $\mathrm{K}$ by analyzing published and field data for a wide variety of earth material types and flow conditions. The found relationship holds:

$$
S P_{c}\left\lfloor k W / m^{2}\right\rfloor=K^{0.75}
$$

\subsection{Comparison for a highly fractured rock with $U C S=175 \mathrm{MPa}$}

Fig. 9 shows the highly fractured rock described in $\S 3.3$ and compares the Fracture Mechanics method of the SCSM with the EIM. The main parameters used for both methods are summarized in Table 1.

\begin{tabular}{|c|c|c|}
\hline Param. & SCSM & EIM \\
\hline $\begin{array}{c}\text { Erosive } \\
\text { capacity of } \\
\text { jet }\end{array}$ & $\begin{array}{c}\mathrm{V}=38 \mathrm{~m} / \mathrm{s}, \mathrm{D}=7.5 \\
\mathrm{~m}, \\
\text { Pmax (Eq.(12)) }\end{array}$ & $\begin{array}{c}\mathrm{V}=38 \mathrm{~m} / \mathrm{s}, \mathrm{D}=7.5 \mathrm{~m} \\
\mathrm{SP}(\mathrm{Eq} .(19))\end{array}$ \\
\hline $\begin{array}{c}\text { Rock mass } \\
\text { strength }\end{array}$ & $\mathrm{UCS}=175 \mathrm{MPa}$ & $\mathrm{Ms}=175$ \\
\hline & & $\mathrm{Kb}=\mathrm{RQD} / \mathrm{Jn}=$ \\
& & $\begin{array}{c}0.25 / 3.34=7.49 \\
(3 \mathrm{sets}+\text { random) }\end{array}$ \\
& $\begin{array}{c}\text { Persistency of fis- } \\
\text { sures }=80 \%\end{array}$ & $\begin{array}{c}\text { Kd }=\mathrm{Jr} / \mathrm{Ja}=1.0 / 1.0 \\
(\mathrm{smooth} \text { planar tight }\end{array}$ \\
$\begin{array}{c}\text { Rock mass } \\
\text { disconti- } \\
\text { nuities }\end{array}$ & $\begin{array}{c}\text { Elliptical shaped, } \\
\text { with lateral sup- } \\
\text { port }\end{array}$ & $\begin{array}{c}\text { joints and unaltered } \\
\text { walls })\end{array}$ \\
& $\begin{array}{c}\text { Max. 1m length } \\
\end{array}$ & $\begin{array}{c}\mathrm{Js}=0.80 \text { (joint spac- } \\
\text { ing 1:2, almost } 90^{\circ} \\
\text { dip) }\end{array}$ \\
\hline
\end{tabular}

Table 1 Main parameters of SCSM and EIM

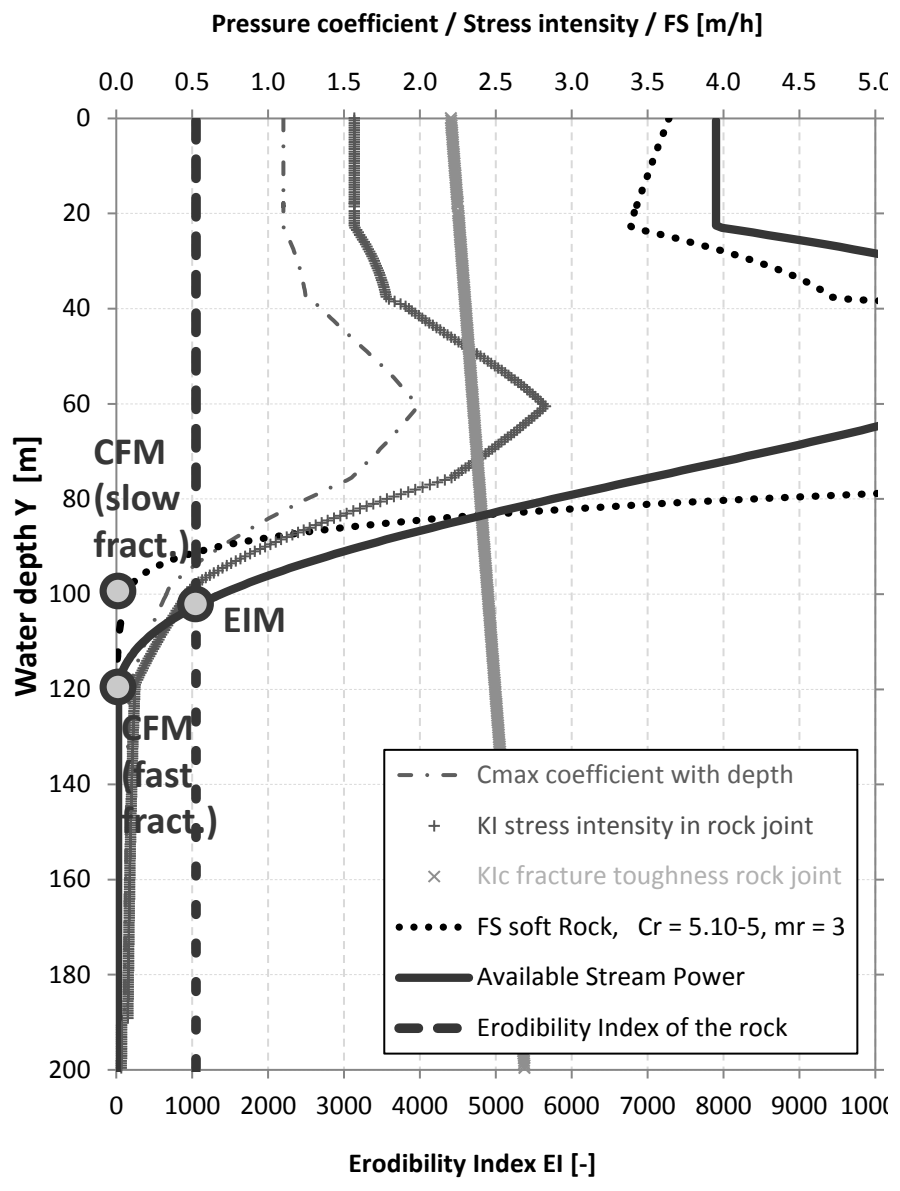

Figure 9 Comparison of SCSM-EIM for highly fractured rock 
The ultimate scour depth estimated by the EIM is about $105 \mathrm{~m}$, i.e. in between the estimates made by the SCSM for fast and slow eroding rock masses.

\subsection{Comparison for a lowly fractured rock with $U C S=175 \mathrm{MPa}$}

Fig. 10 shows the lowly fractured rock described in $\$ 3.4$ and compares the Fracture Mechanics method of the SCSM with the EIM. The main parameters used for both methods are summarized in Table 2 .

\begin{tabular}{|c|c|c|}
\hline Param. & SCSM & EIM \\
\hline $\begin{array}{c}\text { Erosive } \\
\text { capacity of } \\
\text { jet }\end{array}$ & $\begin{array}{c}\mathrm{V}=38 \mathrm{~m} / \mathrm{s}, \mathrm{D}=7.5 \\
\mathrm{~m}, \\
\operatorname{Pmax}(\mathrm{Eq} .(12))\end{array}$ & $\begin{aligned} \mathrm{V}= & 38 \mathrm{~m} / \mathrm{s}, \mathrm{D}=7.5 \mathrm{~m} \\
& \mathrm{SP}(\text { Eq.(19)) }\end{aligned}$ \\
\hline $\begin{array}{l}\text { Rock mass } \\
\text { strength }\end{array}$ & $\mathrm{UCS}=175 \mathrm{MPa}$ & $\mathrm{Ms}=175$ \\
\hline $\begin{array}{l}\text { Rock mass } \\
\text { disconti- } \\
\text { nuities }\end{array}$ & $\begin{array}{l}\text { Persistency of fis- } \\
\text { sures }=10 \% \\
\text { Elliptical shaped, } \\
\text { with lateral sup- } \\
\text { port } \\
\text { Max. } 1 \mathrm{~m} \text { length }\end{array}$ & 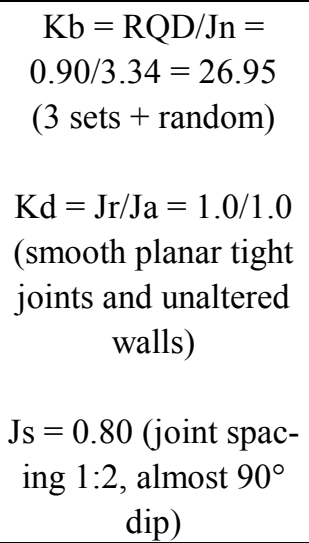 \\
\hline
\end{tabular}

Table 2 Main parameters of SCSM and EIM

The ultimate scour depth estimated by EIM is $80 \mathrm{~m}$, i.e. less than the estimates made by the SCSM. Based on Fig. 7, however, the SCSM ultimate depths would need hundreds of $h$ of discharge to occur.

\subsection{Comparison for a lowly fractured rock with $U C S=50 \mathrm{MPa}$}

Fig. 11 illustrates a similar comparison between the SCSM and the EIM for a lowly fractured rock but with a UCS strength of only $50 \mathrm{MPa}$. Compared with Fig. 10 for a lowly fractured rock but with UCS $=175 \mathrm{MPa}$, both methods indicate deeper ultimate scour depths. However, the tendencies and differences between both methods remain similar.

This can also be observed in Fig. 12, which shows the time evolution of scour formation for a lowly and highly fractured rock but with a UCS $=50 \mathrm{MPa}$. The curves clearly extend deeper than the ones in Fig. 7 for UCS $=175 \mathrm{MPa}$. Also, for a highly fractured rock, the slope of the time evolution becomes more significant, indicating rapid scour deepening as a function of time duration of flood.

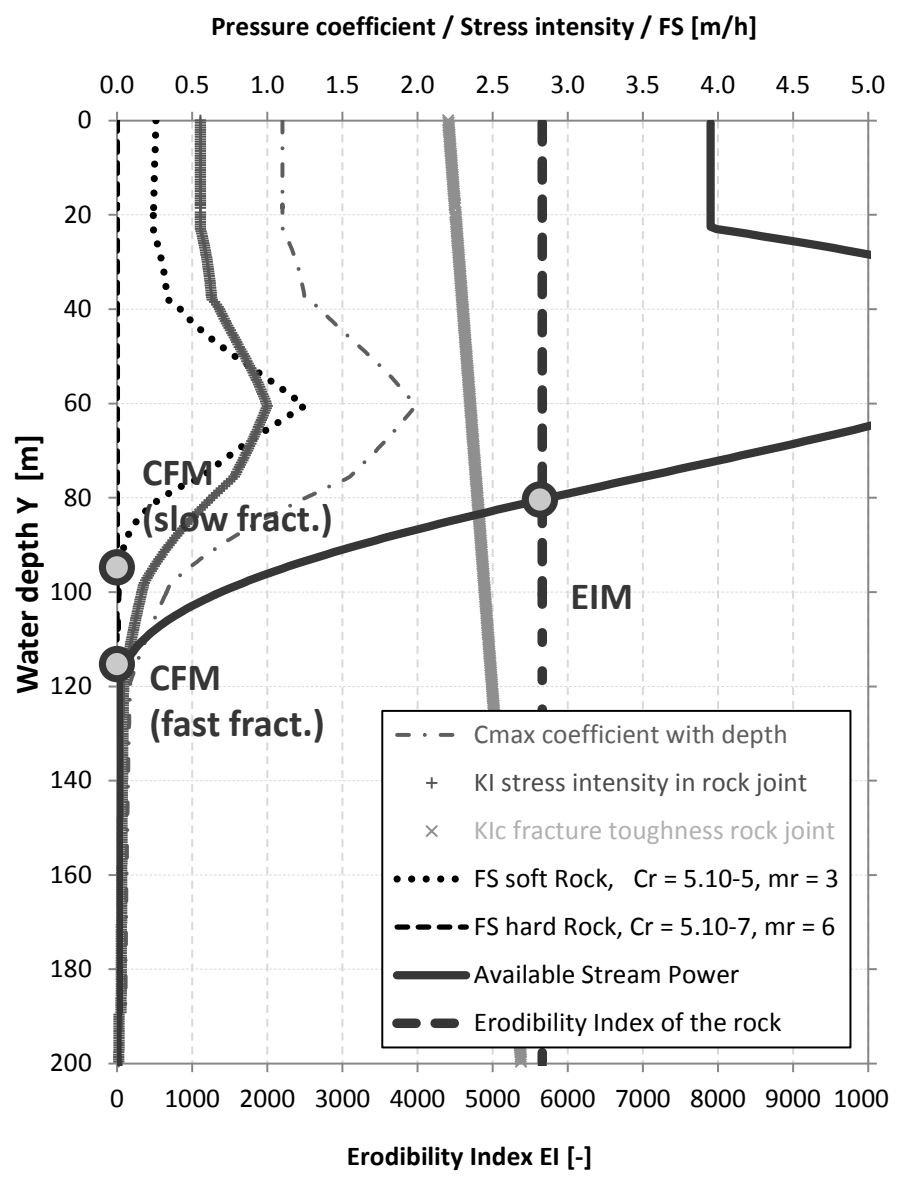

Figure 10 Comparison of SCSM-EIM for lowly fractured rock and $U C S=175 \mathrm{MPa}$

Pressure coefficient / Stress intensity / FS [m/h]

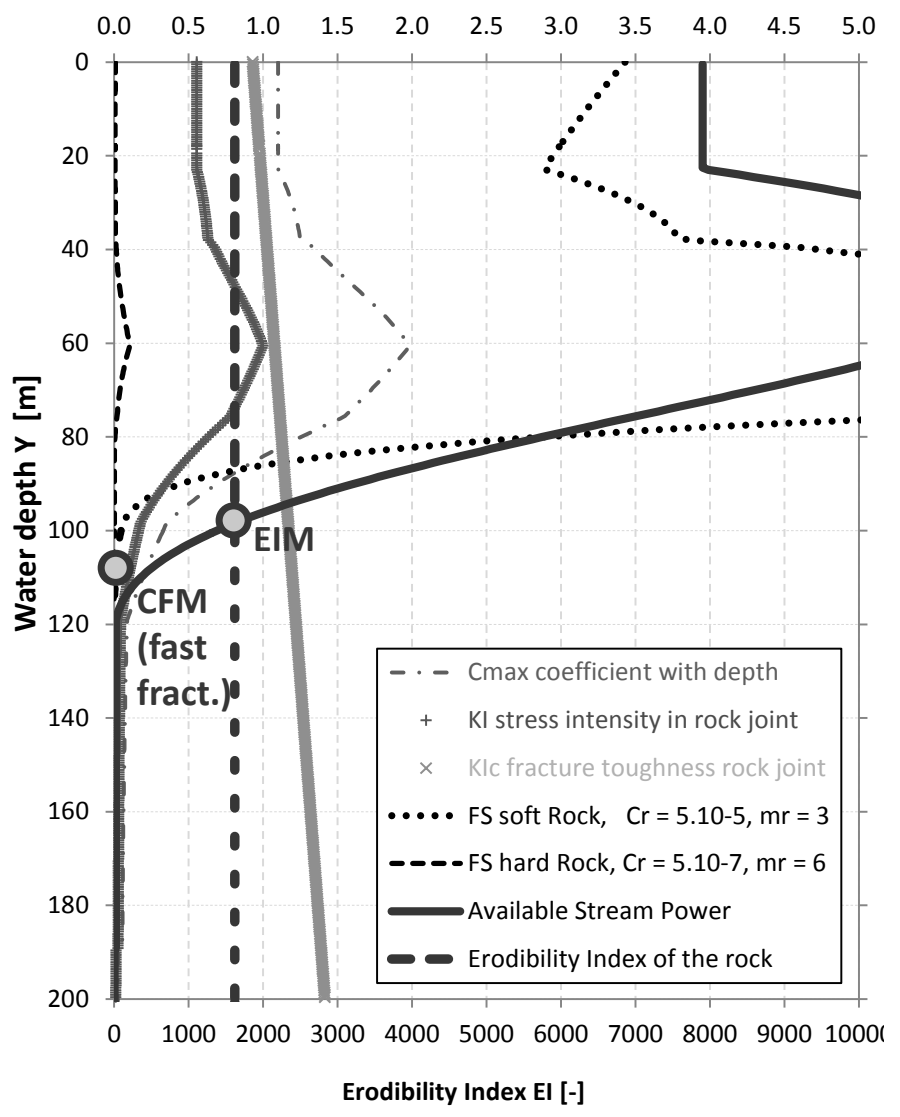

Figure 11 Comparison of SCSM-EIM for lowly fractured rock and $\mathrm{UCS}=50 \mathrm{MPa}$ 


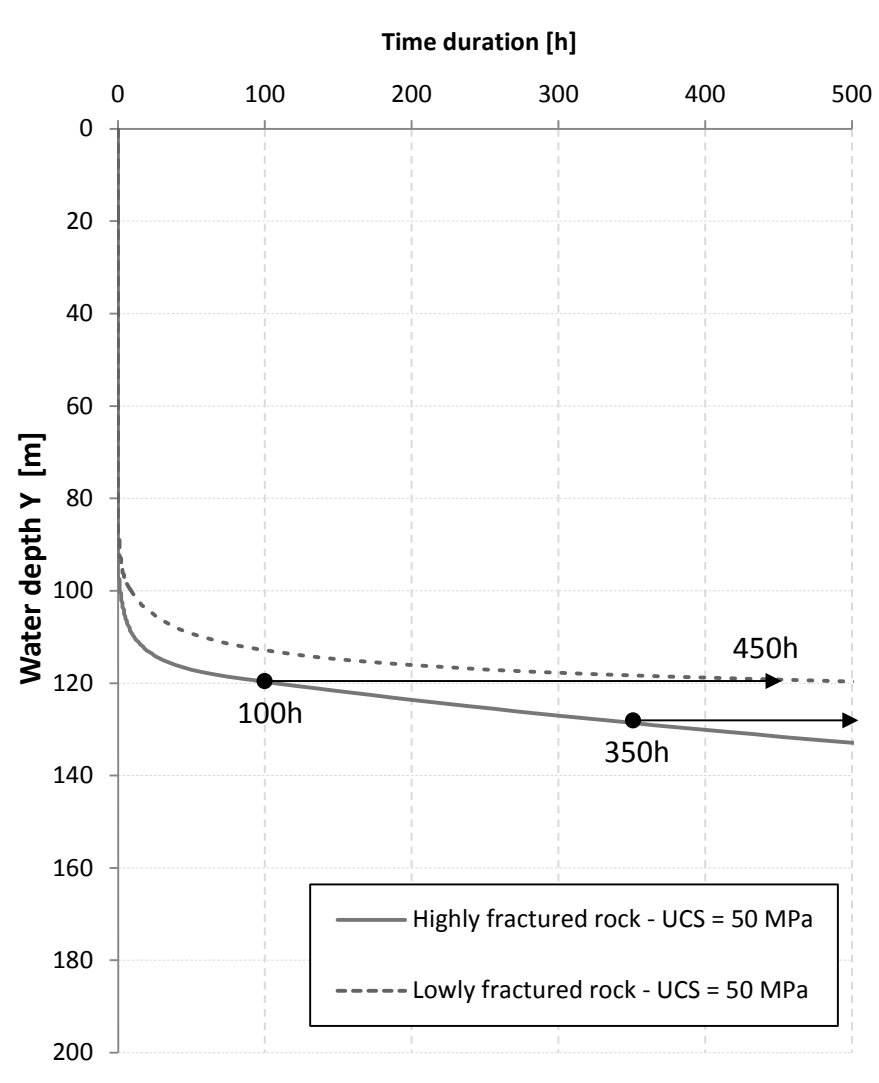

Figure 12 Time evolution of scour formation for a soft rock

\subsection{Summary of comparison SCSM-EIM}

It is interesting to notice the significant agreement between both methods, both in terms of ultimate scour depth and in terms of sensitivity of the ultimate scour depth as a function of the degree of initial fracturing of the rock mass.

First, the UCS strength used in the fracture mechanics approach of the SCSM is directly related to the mass strength number Ms of the EIM approach.

Next, in the SCSM, the degree of initial fracturing of the rock mass is expressed by the persistency of the joint network, while in the EIM it is expressed by the RQD value. In reality, the persistency of the SCSM is most often being defined based on RQD values and in situ and borehole observations of the number of joints (Jn number of EIM), which explains its similarity with the EIM approach.

Furthermore, the Js (relative ground structure) number of the EIM is related to the rock block shape ( $\mathrm{z} / \mathrm{x}$ flatness) being used by the DI method of the SCSM.

Finally, the Kd (discontinuity bond shear strength) number has not really an equivalent in the SCSM, but is more or less related to the type of joints, i.e. with or without lateral support, which expresses the easiness of fracturing of the joint.

Beside the ultimate scour depth, the SCSM is able to provide also an estimate of the time evolution of scour formation, which is not possible with the EIM.

\section{CONCLUSIONS}

Application of the Simplified Comprehensive Scour Model (SCSM), valid at the point of jet impact and using simplified expressions for circular jets, allows a more straightforward and less cumbersome assessment of the ultimate scour depth as well as of the time evolution of scour formation.

For this, the main parameters of interest are being quantified in a broad-brush manner, based on reasonable assumptions, without any detailed calibration of the different rock break-up modules of the SCSM.

The outcome provides a first-hand estimate of the ultimate scour depth and of the time duration of discharge needed to get there.

Despite its interesting agreement with the Erodibility Index Method (EIM), use of the SCSM should be reserved for preliminary design purposes only. For more advanced design stages of a project, or for detailed dimensioning of scour mitigation measures, application of the more complete and detailed CSM is strongly suggested, even in cases where no calibration of the model is available.

\section{REFERENCES}

Annandale, G. 1995. Erodibility. Journal of Hydraulic Research, IAHR, Vol. 33, N4,: 471-494.

Annandale, G. 2006. Scour Technology: Mechanics and engineering Practice. McGraw-Hill.

Beltaos, S.; Rajaratnam, N. (1973). "Plane turbulent impinging jets." Journal of Hydraulic Research, IAHR, Vol. 11, N ${ }^{\circ} 1$, pp. 29-59.

Bollaert, E. F. R. 2002. Transient water pressures in joints and formation of rock scour due to high velocity jet impact, $P h D$ Thesis, Ecole Polytechnique Fédérale de Lausanne (EPFL), Lausanne, Switzerland.

Bollaert, E.F.R. (2004). "A comprehensive model to evaluate scour formation in plunge pools." Int. J. Hydropower \& Dams, 2004, 2004(1), pp. 94-101.

Bollaert, E.F.R. and Hofland, B. (2004). The Influence of Flow Turbulence on Particle Movement due to Jet Impingement, 2nd Scour and Erosion Conference, Singapore, November 2004.

Bollaert, E.F.R. 2012. Wall-jet rock scour in plunge pools: a quasi-3D prediction model. Intl. Journal of Hydropower and Dams, 2012.

Reich, F. (1927). "Umlenkung eines Freien Flüssigkeitsstrahles an einer ebenen Platte." Zeitschrift Verein deutscher Ingenieure 71 (8): p. 261-264. 